\title{
Double pyloric ostium, an extremely rare endoscopic finding, in a 62-year-old male patient presenting with melena
}

\author{
Umid Kumar Shrestha, MD, PhD, FACG
}

Department of Gastroenterology and Hepatology, Nepal Mediciti Hospital, Bhaisepati, Lalitpur, Nepal

DOI: https://doi.org/10.3126/jaim.v7i2.23494

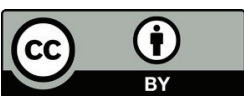

This work is licensed under a Creative Commons Attribution 3.0 Unported License.

\begin{abstract}
Question
A 62-year-old male was presented with melena for 2 days. He used to take non-steroidal anti-inflammatory drugs on and off for the gouty arthritis and had developed tophi over the right first metatarsophalangeal joint. His physical examination revealed tachycardia of 110 beats per minute and a blood pressure of $100 / 70 \mathrm{~mm} \mathrm{Hg}$. A complete blood count revealed hemoglobin level of $9.3 \mathrm{~g} / \mathrm{dl}$ with normal platelet and leucocyte count. His serum uric acid level was $7.3 \mathrm{mg} / \mathrm{dl}$. He underwent upper gastrointestinal endoscopy for the further evaluation. His endoscopic examination finding is shown in the following picture. What is the diagnosis?
\end{abstract}

\begin{abstract}
Answer:
The upper endoscopic examination of the patient revealed two channels in the pylorus region and there was an ulcer at the gastric side of the acquired channel, with an evidence of bleeding from the ulcer. The endoscope could be passed through both of the channels from the antrum to the duodenal bulb. The site of the bleeding point was coagulated for securing the hemostasis. In this patient, the fistula arising between the stomach and duodenum bulb resulted in the appearance of a double pylorus, which was first described in 1969 by Smith and Tuttle. ${ }^{1} \mathrm{~A}$ double pylorus is a rare endoscopic finding that has been reported in $0.001 \%$ to $0.04 \%$ of upper gastrointestinal endoscopies. ${ }^{2}$ The double pylorus an acquired complication of chronic peptic ulcer disease. ${ }^{3}$ It is found incidentally or present with epigastric pain, dyspepsia or upper gastrointestinal bleeding. Most patients respond well to anti-ulcer medication, but fistula closure did not occur in the majority of patients in long-term follow-up. Gastroenterologists should be aware that double pyloric ostium can occur as an acquired complication of chronic peptic ulcer disease.
\end{abstract}

Keywords: Peptic ulcer disease; complication; double pyloric ostium

\section{Reference:}

1. Smith VM, Tuttle KW. Gastroduodenal (pyloric) band. Gastroenterology 1969;56:331-6.

2. Wiseman SM, Tan D, Hill HC. Double pylorus: an unusual endoscopic finding. Endoscopy 2005;37:277.

3. Lee S-Y, Kim E-S, Cho Y-S. Gastrointestinal: Acquired double pylorus; long term endoscopic observation. J Gastroen Hepatol 2012;27:413.
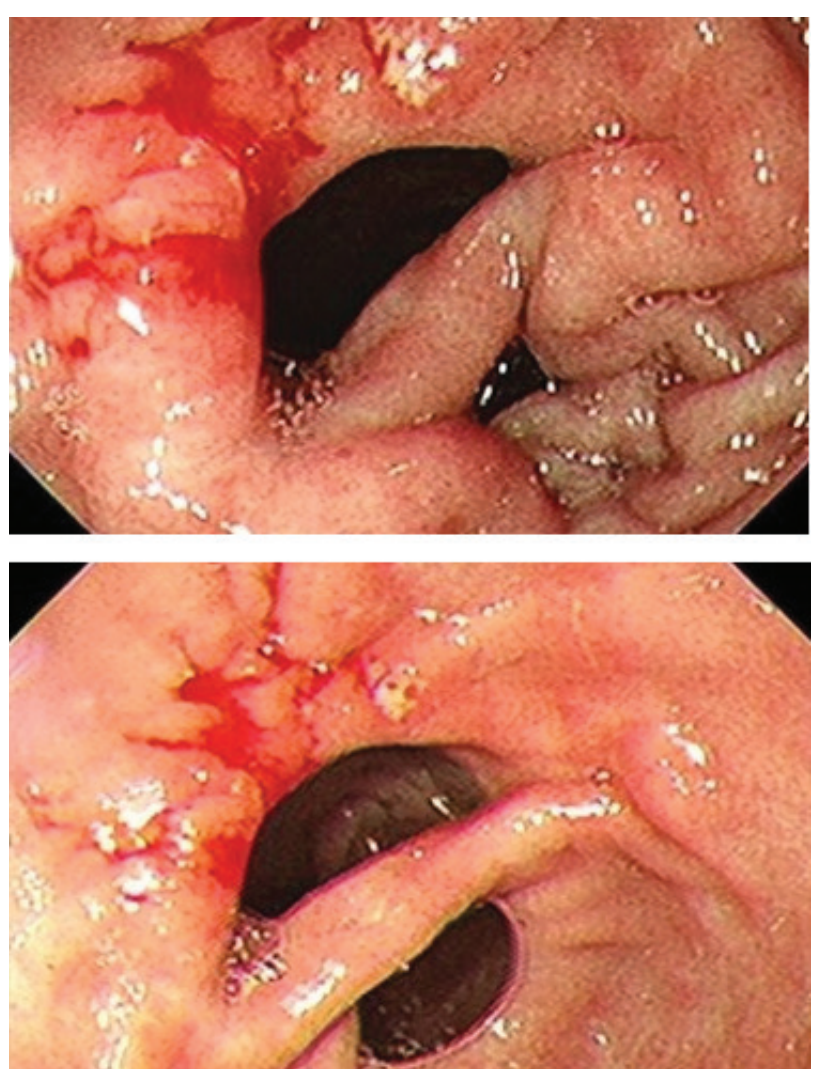

\section{Correspondence Author}

Umid Kumar Shrestha

$\mathrm{MD}, \mathrm{PhD}$, FACG

Department of Gastroenterology and Hepatology

Nepal Mediciti Hospital, Bhaisepati, Lalitpur, Nepal

Email: umidshrestha@gmail.com 